\title{
DEATH OF AN OSPREY
}

\section{DENNIS FISHER, 72 Richmond Crescent, Saskatoon, SK S7K 1 A8}

An October drive along our rivers is always a pleasant trip. The fall colours of yellow and red mix with the lasting greens to present a beautiful sight. A trip like this can also yield some exciting and rare sights. That was the case, when my wife Jeannie and I took "birder" Lynne Salisbury on a trip to the heart of the Northwest....Batoche. It was October 1 st, we had just finished lunch at the National Historic Site, and were talking about the Mountain Bluebirds that were flitting about the area. We wondered if they were telling us something about "Indian Summer". Minutes later we were on the road and heading for the St. Laurent ferry. A mile south of the ferry we noticed a large raptor, circling close to the roadway. We slowed down as it circled near us. What was it? "It has got so much white on it" Lynne said. As it went by I noticed a mask on its eyes, and the wing dihedral. "I don't think it's a Buteo" someone said. Just then, things changed. The bird put its wings close to its body and started a power dive. It plunged and disappeared from sight.

I pulled the van to the side of the gravelled road. "Come on! It has got something, let's take a look!" I said as I parked the van. I thought we would cross the ditch to see a grassy patch below the hill crest, with our bird sitting with its prey. Maybe it would take to the air with a tiny mouse in its talons. We were in for a surprise. When we reached the crest we found out we were on the uppermost edge of a cliff. The river was about 70 feet below us. No grass, no bird and no mouse! In a few seconds we found our bird. It was in the water, about 2 feet from shore, in shallow water. The huge wing attracted attention as it flapped in the murky water. There were still lots of bubbles on the surface and from our high vantage point, we could see the unsettled silt drifting away from the kill site.

Now, we could really see the bird and its markings. "It is an Osprey" cried Lynne. We were excited. As it toiled with its stubborn prey, still in the water, we could see the white specks on its back and wings. It was an immature Osprey! The Osprey was trying to get its catch ashore and was having trouble. We thought soon we would see the silvery form of a Sauger, Goldeye or Sucker, but we were wrong. When it got on the stony shore it had a brownish-grey form in its right talons! It was a medium-sized Muskrat. Lynne had a good pair of glasses with her so we took turns getting a closer look at this uncommon sight. You could see the Muskrat's tail. You

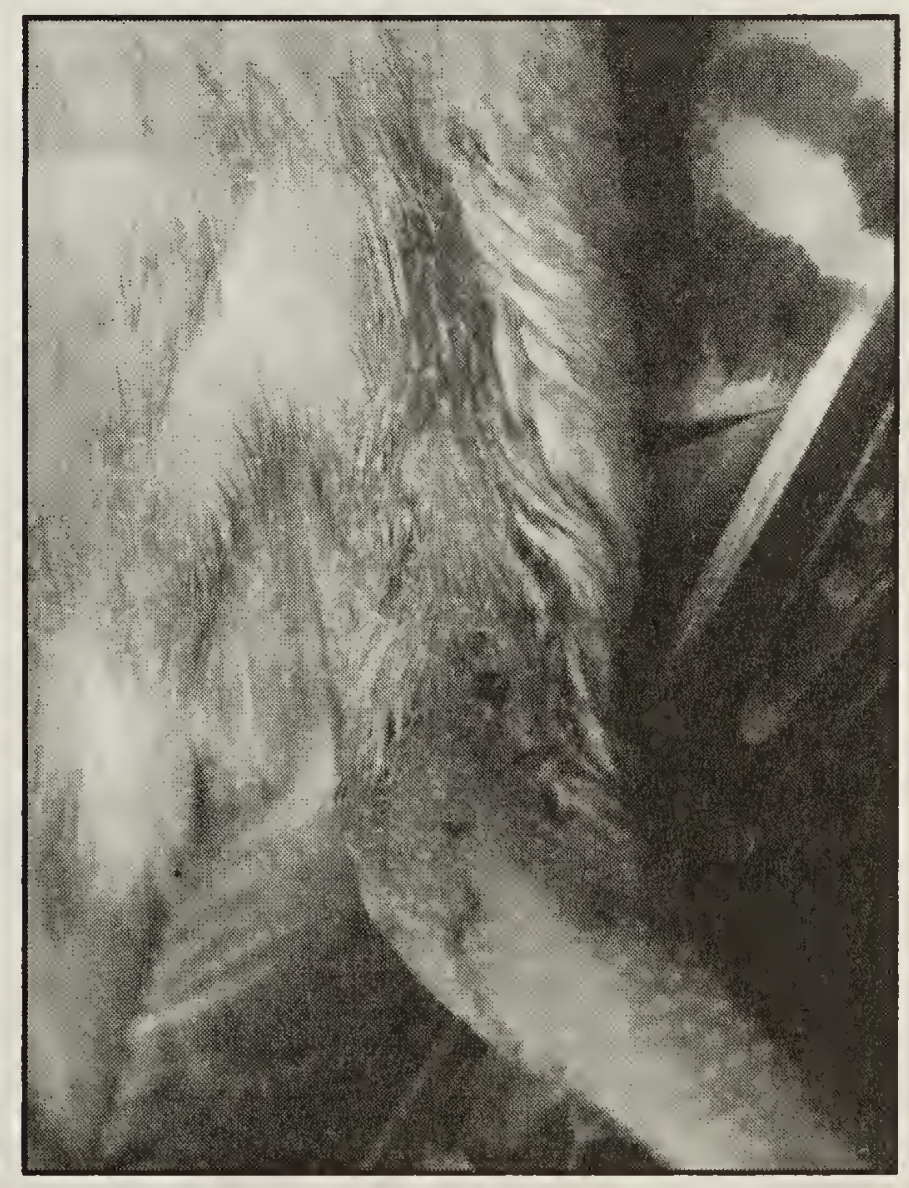

Leg of Osprey killed by Muskrat

Mary Houston 
could also see a sense of confusion. It appeared as though this young Osprey did not know what to do with its "catch of the day"...and there was neither mom nor dad nearby, to ask. He looked confused as he struggled. With the glasses, I noticed fresh, bright red blood streaming from the Osprey's left shank. Was this Muskrat or Osprey blood? It was now about 3:15 pm and the contest was evenly matched. I wandered away, while Lynne and Jeannie kept careful watch. They told me the Osprey only pecked the Muskrat on one occasion. After about twenty minutes the Osprey had pulled the struggling Muskrat to a small, flat-surfaced rock. Atop this rock, it assumed what I call a "cluck hen" position: its wings out slightly, like a mother hen on her brood. The Muskrat was beneath the Osprey, still in its right talons, and time went on.

I suggested the Osprey was just being patient and planned on waiting until life had ebbed from the Muskrat. When he felt the final stillness, he would begin his meal of the day. We decided to move on. We had seen something special. "Wait till Stuart and Mary Houston hear about this!" I said, remembering these special people, "Yes, and Stuart will give you heck for not staying until the conclusion" remarked Lynne. We continued on and by the time we reached home that evening we had speculated on all the possible outcomes. So we thought, but there would be outcomes we could not even imagine. That's the rest of the story.

The next morning, about 8:30 am, I told myself I should phone our area's favourite birdman, and I called Dr. Stuart Houston. At this point I feel like writing about three pages on the Houstons, these very special people, but then I realize that anyone who reads to the second page of this article, knows the Houstons. After the pleasant words of greeting, I said: "Stuart,...Jeannie, Lynne Salisbury and I saw an Osprey take a Muskrat from the river, yesterday!. Nearly interrupting, Stuart proclaimed "Could be a world first! "....Mary, please get on the extension, Dennis Fisher's on the line with an Osprey story!" he added.

I went on with the story, recalling the sequence of events and the times, locale and who all saw what. I was excited again. We talked ospreys, their habits and traits. Stuart was sure this could be a world first. To non-birders in the crowd this may be like seeing a Whooping Crane lay an egg!.... and we saw it with our very own eyes! We talked on. We talked about the blood on the Osprey's leg and Stuart told me an Osprey's blood has poor coagulation factors, and that if the Muskrat bit the Osprey, we might find a dead Osprey.

Now, the scientist in Stuart was coming out. Stuart wanted the fool-proof evidence he could take to his peers. The Houstons are good friends with Alan Poole, a world authority on Ospreys. I wanted to believe this might be a first world sighting. We talked about the remains of the Muskrat and I offered to take Stuart to the location, 60 miles north of Saskatoon. He couldn't go because of his busy life, but could we go and bring back the evidence? I told him we would leave at 9:30 am and do what we could. I would bring a camera and photograph the site, blood, etc. Then I called Lynne Salisbury and told her we were not finished....she excitedly agreed to come with us.

A fresh batch of sandwiches, a few thermos bottles, and we were on our way. As we drove, we exchanged information we garnered from bird books overnight. Yes, Ospreys were known to sometimes take "small mammals". Would that include Muskrats? We got 


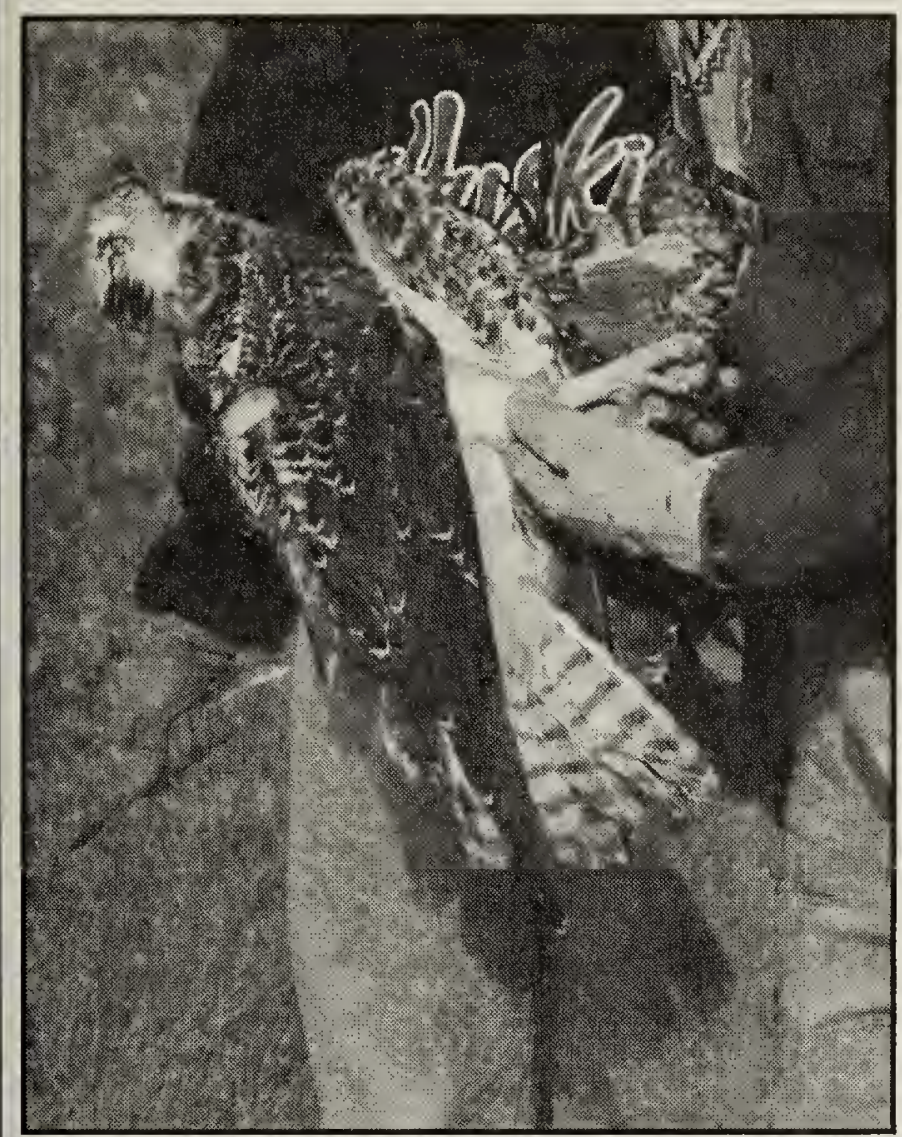

Young Osprey killed by Muskat

Dennis Fisher

to the site about $11: 15$ am on a bright October 2nd, 1997. I had a variety of camera lenses with me and we would record the site on film. First we went to the cliff edge where we made our observations and photographed the water's edge below. I took some wideangle and telephoto $(200 \mathrm{~mm})$ shots of the kill site. Then the three of us made our way, down the steep, sandy slope. We held on to shrubbery in the tough spots, but soon we were water side. Plainly and simply there were no Muskrat remains at the site. There was no blood on the flat rock, where we last saw the Osprey. We saw some feathers and that excited us, until we realized there were feathers in the water all along the river shore. We had lost our excitement "of the chase" and we were now "down". We had no evidence for Stuart Houston. Could we go back to Saskatoon?

We did not know how to think like a juvenile Osprey, but we decided to check the river's shoreline, hoping he had chosen another picnic site. We went south, about 500 yards and found nothing of interest. No signs. Nothing. Well, let's go north. We walked about 150 feet North and there in the green grass of the shore we saw the dead body in the grass. It was not the Muskrat. Stuart was correct, we found a dead Osprey. It was a shallow victory, a sad win. So much for science, but we did not feel good. The young Osprey was not the winner. The Muskrat as probably dead or dying in some bank tunnel. We looked, but found no trace of it. We took a few in-situ photos before we moved the body. At this point we did not know that the Muskrat was visible in the background. We took the Osprey, phoned Mary from Batoche and followed her directions. We delivered it to the Houston home. Mary met us at the door with a freshly banded Junco in her hand. We retold the story and photographed Mary with the Osprey. The wounds on the legs were plainly visible. Mary photographed the leg with the macro lens of my camera. We had brought back what evidence we could. 